\title{
The Effect of Creating Opportunities for Parent Empowerment Program on Parent's Mental Health: A Systematic Review
}

\author{
Mojgan Mirghafourvand, ${ }^{1}$ Elaheh Ouladsahebmadarek, ${ }^{2}$ Mohammad Bagher Hosseini, ${ }^{3}$ Seifollah \\ Heidarabadi, ${ }^{4}$ Mohamad Asghari-Jafarabadi, ${ }^{5}$ and Shirin Hasanpour ${ }^{2,}$ \\ ${ }^{1}$ Department of Midwifery, Tabriz University of Medical Sciences, Tabriz, Iran \\ ${ }^{2}$ Women's Reproductive Health Research Center, Tabriz University of Medical Sciences, Tabriz, Iran \\ ${ }^{3}$ Pediatric Health Research Center of Tabriz, Tabriz University of Medical Sciences, Tabriz, Iran \\ ${ }^{4}$ Department of Pediatrics, Tabriz University of Medical Sciences, Tabriz, Iran \\ ${ }^{5}$ Department of Statistics and Epidemiology, Tabriz University of Medical Sciences, Tabriz, Iran \\ "Corresponding author: Shirin Hasanpour, Women's Reproductive Health Research Center, Alzahra Hospital, Artesh St., Tabriz, Iran. Tel: +98-9141151057, E-mail: \\ shirinhasanpoor@yahoo.com
}

Received 2016 February 14; Accepted 2016 September 30.

\begin{abstract}
Context: Premature birth and the consequent neonatal intensive care unit (NICU) admission cause parents great distress, which makes them in need of support when their infant is hospitalized at the NICU.

Objectives: The aim of this study was to determine the impact of creating opportunities for parent empowerment (COPE) program on parents' mental health. This review emphasizes on mental disorders' prevention.

Data Sources: This systematic review was performed by searching the databases including Cochrane Library, PubMed, Scopus, Google Scholar, Proquest, Science Direct, SID, Magiran and Iranmedex databases for interventional papers from 2000 to 2015.

Study Selection: The studies, which were considered for this review included, randomized controlled clinical trials and quasiexperimental studies on the impact of COPE program on the mental health of premature infants' parents.

Data Extraction: For determination of eligible studies, two authors extracted the data independently and discrepancies were resolved through discussion or, if required, through consultation with a third author.

Results: Only four studies conducted on the impact of COPE program on parents' mental health were included in this systematic review. According to these studies, the implementation of COPE program for the parents of premature infants hospitalized at the NICU decreased stress significantly after the second phase of the COPE program (-1.72 (95\% CI:-1.97,-1.47)) and state anxiety after first phase of program (-1.01 (95\% CI:-1.48, -0.53)) in mothers.

Conclusions: The studies suggested the positive impact of COPE programs on parents' mental health; however, more studies are recommended on all aspects of mental health along with further involvement of fathers.
\end{abstract}

Keywords: Mental Health, NICU, Empowerment, Parents

\section{Context}

Preterm labor is a global health problem, which is still increasingly growing, despite the great efforts made to prevent it (1). According to the statistics published by the world health organization, 15 million infants are annually born preterm in the world. Most of them are born in Asia and Africa (2). The incidence rate of preterm labor has been reported to be $8.4 \%$ in Iran (3).

Advances in technology have decreased the death rate of these infants; however, the side effects caused by preterm labor, such as developmental problems, are still observed among them. These problems impose a great financial and emotional burden on the families and health systems. Following the birth of a premature infant and hospitalization at the NICU, parents, especially mothers, experience stress, anxiety, guilt, helplessness and depres- sion (4-6). These disorders usually result from mother's insufficient information on how to play the parental role and how to interact with the infant during hospitalization (7). Moreover, the NICU's over-technical environment and premature infant's appearance and behaviors disrupt the formation of parental role and decrease the quality of parentinfant interaction (1). These primary problems often cause parents to become overprotective, which leads to disruption in the infants' physical, emotional growth and development. Various studies indicated that severe depression and stress were among the most important risk factors of subsequent behavioral disorders. On the contrary, stress reduction may increase the parents' awareness regarding the symptoms of their children, and improve parent-child interaction $(1,7)$.

Studies indicated that mother's participation in daily 
cares of infants at the NICU, lead to the formation of positive feelings. Therefore, it appears necessary to implement a parental support and empowerment program during the hospitalization of the infant at the NICU in order to increase essential knowledge and skills. This in fact can be a key factor in the formation of healthy mother-infant interactions and positive outcomes (4).

One of these supportive programs is the creating opportunities for parent empowerment (COPE) program, which was developed by Dr. Bernadette Melnyk (1). The theoretical framework of the program is based on selfregulation (Johnson, Fieler, Jones, Wlasowics, and Mitchell, 1997; Levental and Johnson, 1983) (8, 9) and control theories (Carver, 1997) (10). The aim of this program is to enhance parents' knowledge and ideas about their premature infants, improve parenting role, and remove barriers to their participation in caring for their infants $(11,12)$.

The COPE is a behavioral-training intervention program consisting of four phases, each of which has a particular audio-tape and training manual (1). Phase 1: from two to four days after hospitalizing the infant; this phase includes training on the infant's characteristics and special behaviors with emphasis on the way they are different from term infants, and the NICU environment. Moreover, this phase includes particular strategies to help parents become involved in caring for their infant at the NICU. Phase 2: from two to four days after the first phase, including complementary information on the premature infant's behavior and development as well as more recommendations pertaining to the way parents participate in caring for their infant and help to improve the infant's development. Phase 3: from one to three days before the infant is discharged; this phase includes information on infant's development, parents' role in transferring the infant from hospital to home, and the way positive motherchild interactions are continued. Phase 4: one week after discharge from the NICU, including information about infant's behavior and parents' role on the constant growth and development of the infant and recommendations for the improvement of positive parent-infant interaction as well as parents' particular activities for increasing the infant's cognitive development. The duration of each COPE audio tape is about 10 to 20 minutes. After listening to these tapes and reading the training manuals, parents acquire skills on how to care for their premature infant (1214).

Numerous studies have been conducted on the impact of training-behavioral interventions for parents of premature infants (15-17); however, to the best of our knowledge, no critical appraisal is done on the impact of the COPE program on the mental health of the parents of premature infants and none of the previous systematic reviews was re- lated to the recent RCTs. According to the evidence from interventional studies on the subject, some suggestions were made in order to convey the knowledge from findings of such studies to the bedside.

\section{Objectives}

The aim of this study was to determine the impact of creating opportunities for parent empowerment (COPE) program on parents' mental health. This review emphasized on mental disorders' prevention.

\section{Data Sources}

The search for systematic reviews on the study subject started from Cochrane database. There were no systematic reviews conducted on the impact of the COPE program on the mental health of premature infants' parents. Using keywords of "premature infant", "mental health", "NICU", "COPE Program", "stress", "anxiety", "depression" and "parents", a search was carried out in the databases of Cochrane, PubMed, Scopus, Google Scholar, Proquest, Science Direct, SID, Magiran and Iranmedex from 2000 to 2015.

The references of included papers were investigated. The theses were looked up on the websites of universities and Iran doc. The selected proceedings and abstracts from conferences were investigated in order to obtain grey literature.

\section{Study Selection}

Inclusion criteria included publications from 2000 to 2015, those written in Persian and English and investigating the impact of the COPE program on the mental health of premature infants' parents.

The studies, which were considered for this review, included randomized controlled clinical trials and quasiexperimental studies.

The inclusion criteria were based on PICOS:

The participants were the parents of premature infants with gestational age between 26 and 37 weeks, hospitalized at the NICU, and birth weight of less than 2500 grams. All infants were the result of singleton pregnancies without congenital disorders.

The COPE program was implemented in the intervention group, whereas the control group received a training program pertaining to hospital services, discharge information and immunization.

Primary outcome: dimensions of parents' mental health including stress, anxiety and depression. 
Secondary outcome: parents' participation in caring for their infant.

Critical appraisal skills program (CASP) was used to evaluate the quality of papers. Two of the authors separately investigated the studies found in the search in terms of the inclusion criteria. The differences were discussed, and the third author was asked for opinions. Finally, four papers from 102 papers were identified as eligible (Table 1).

\section{Data Extraction}

We designed a form to extract data. For eligible studies, two authors extracted the data independently using the agreed form. Discrepancies were resolved through discussion or, if required, through consultation with the third author.

\section{Assessment of Bias Risk in the Included Studies}

The bias risk was investigated separately by two of the authors in four studies based on the Cochrane manual for systematic reviews (18). The disagreements were resolved after discussing and consulting with the third author. All four studies were investigated in terms of selection bias (considering how to generate allocation sequence and concealment of allocation), performance bias (blindness of participants, personnel and outcome assessors), attrition bias (incomplete outcome data), and reporting bias (selective reporting) (Table 2, Figure 1).

\section{Results}

The four included studies, which investigated the impact of the COPE program on parents' mental health, were critically reviewed (Table 2 ). The paper descriptions are as follows:

Paper 1: This was an RCT conducted to examine the impact of the COPE program on the cognitive development of premature infants and their mothers' coping. It was carried out at one of the university hospitals in New York, 2001. In the COPE group, the mothers received a fourphase training-behavioral program, which commenced from two to four days after labor and lasted until one week after discharge from the NICU. The control group received written and audio information on hospital services, routine discharge and immunization. Maternal stress was evaluated during intervention phase 3 at the NICU. State of anxiety and maternal stress were assessed during phases 2, 3 and 4, and the infant's corrected age of three and six months. Results indicated that COPE mothers reported significantly lower stress at the NICU. However, no statistically significant difference was observed between the groups in terms of depression and anxiety (1).

Paper 2: This study was an RCT conducted to determine the impact of the COPE program on reducing the length of hospitalization and increasing the mental health of premature infants from September 2001 to October 2004 at two NICUs in the Northern America. In the intervention group, all participants received four phases of the COPE program, whereas the participants in the control group received information on hospital services and policies. The main study variables included stress, anxiety, depression, beliefs and infant-parent interaction during the stay at the NICU, the length of stay at the NICU, and the overall length of hospitalization.

Results indicated that the COPE mothers reported significantly lower stress at the NICU. At infant's corrected age of two months, mothers' anxiety and depression were significantly lower than the control group, whereas parents' symptoms of anxiety and depression after discharge from the NICU were not different from the control group (12).

The secondary analysis of this study's data indicated that participation in the COPE program was associated with depression and anxiety after mothers' discharge through important variables such as mother's belief and stress at the NICU as well as mother's anxiety and depression during their stay at the NICU. Therefore, providing mothers with the COPE program strengthened their opinions and beliefs about the characteristics of their infant and parenting role. It decreased their stress, anxiety and depression symptoms during the stay at the NICU. It also reduced symptoms of anxiety and depression after discharge (19).

Another study, which was another secondary analysis of current research data, was also conducted on stress reduction in children born prematurely and their young mothers. It investigated the anxiety of children and mothers with scales of state-trait anxiety inventory and child behavior checklist for ages two to three at the age of 24 months after two to four days of intervention (four to eight days after hospitalization at the NICU). Results indicated that participation in the COPE program predicted significant stress reduction in mothers aged between 18 and 21 years; however, this was not true about those who were older than 21 (20).

Paper 3: This was a quasi-experimental study conducted on the impact of the COPE program on maternal stress at the NICU in three hospitals affiliated with Tehran University of Medical Sciences in Iran from May 2009 until May 2010. The COPE program was provided for the intervention group mothers, whereas the control group mothers received routine training. Maternal stress was assessed through the Parental Stressor Scale. Results indicated that 
Table 1. Summary of Studies Carried out on the Impact of the Creating Opportunities for Parent Empowerment Program on the Mental Health of Parents

\begin{tabular}{|c|c|c|c|}
\hline Study & Sample & Design and Intervention & Major Findings \\
\hline Melnyk et al. (2001) & $\begin{array}{l}42 \text { mothers of low birth weight premature } \\
\text { infants, } 26 \text { to } 36 \text { weeks of age and a weight } \\
\text { less than } 2500 \text { grams }\end{array}$ & $\begin{array}{l}\text { RCT pilot study with follow-up until the } \\
\text { corrected age of } 3 \text { and } 6 \text { months with two } \\
\text { groups; recipient's of the COPE program } \\
\text { and, the control group, recipient's of } \\
\text { routine training }\end{array}$ & $\begin{array}{l}\text { COPE mothers reported significantly less } \\
\text { stress at the NICU. }\end{array}$ \\
\hline Melnyk et al. (2006) & $\begin{array}{l}260 \text { parents of premature infants, } 26 \text { to } 34 \\
\text { weeks and birth weight less than } 2500 \mathrm{~g}\end{array}$ & $\begin{array}{l}\text { RCT with a follow-up at the corrected age of } \\
2 \text { months with two groups (recipient's COPE } \\
\text { program, and the control group, recipient's } \\
\text { routine training) }\end{array}$ & $\begin{array}{l}\text { COPE mothers reported significantly less } \\
\text { stress at the NICU. At the corrected age of } 2 \\
\text { months, anxiety and depression in mothers } \\
\text { was significantly less than the control } \\
\text { group. }\end{array}$ \\
\hline Borimnejad (2013) & $\begin{array}{l}140 \text { mothers with premature infants, } 28-37 \\
\text { weeks and birth weight of less than } 2500 \mathrm{~g}\end{array}$ & $\begin{array}{l}\text { Semi experimental design with two groups } \\
\text { (recipient's COPE program, and the control } \\
\text { group, recipient's routine training) }\end{array}$ & $\begin{array}{l}\text { Stress scores were significantly lower in the } \\
\text { intervention group }\end{array}$ \\
\hline Mianaei (2014) & $\begin{array}{l}90 \text { mothers with premature infants, } 26-34 \\
\text { weeks and birth weight of less than } 2500 \mathrm{~g}\end{array}$ & $\begin{array}{l}\text { RCT with two groups (recipient's of the } \\
\text { COPE program, and the control group, } \\
\text { recipient's of routine training) }\end{array}$ & $\begin{array}{l}\text { Mothers in the intervention group reported } \\
\text { significantly less anxiety and stress after } \\
\text { each phase of the COPE program, while the } \\
\text { control group's stress levels increased. }\end{array}$ \\
\hline
\end{tabular}

stress grades were significantly lower in the intervention group (7).

Paper 4: This was an RCT conducted on the impact of the COPE program on stress, anxiety and participation among the mothers of premature infants hospitalized at the NICUs of hospitals affiliated with Isfahan University of Medical Sciences, Iran, from September 2009 to February 2010. The intervention group received two phases of the COPE program, which included the information and behavioral activities on the characteristics of premature infants. These two training phases were carried out two to four days apart from each other. The control group received routine care; however, they were provided with a training manual and audio-tapes pertaining to phases 1 and 2 of the COPE program after the intervention. The stress and anxiety were evaluated during each phase and two to four days after the second phase. Mothers in the control group reported significantly lower anxiety and stress after each phase of the COPE program, while the stress level increased in the control group. Furthermore, the level of participation of mothers in caring for their infant was higher in the COPE group (4) (Table 1).

\section{Statistical Analysis}

The data pertaining to stress and anxiety obtained from the three studies (there was no sufficient information on the stress evaluation phases in the study conducted by Borimnejad et al., 2013, so it was not included in the metaanalysis) were combined using the RevMan software. The results of meta-analysis indicated a significant statistical difference in the level of maternal stress after the second phase of the COPE program (-1.72 (95\% CI: -1.97, -1.47)) and state anxiety after first phase of the program (-1.01 (95\% CI: $-1.48,-0.53)$ ) between COPE and control groups (Figures 2 - 4). No meta-analysis was conducted for depression because it was only evaluated in two studies, and the appraisal phases were different.

\section{Discussion}

Employing a program to empower the parents of premature infants in the NICU and to increase their knowledge, awareness, incentive and self-efficacy would improve the health and quality of parent's life. The COPE is one of such programs. Limited studies have been conducted on the impacts of the COPE program on parental mental health. The results of the current review indicated the positive impact of the COPE program on the mental health of mothers whose infants were hospitalized in NICUs.

In the study conducted by Melnyk (2001), which was a pilot study on this subject, anxiety and depression in the intervention group were not significantly different from those of the control group. However, stress was reduced in the intervention group. The insignificance of results in all aspects of mental health might be due to the small sample size (1).

The most important study about the impact of the COPE program on mental health of parents was the one conducted by Melnyk (2006). It was carried out with the participation of 260 parents. The most important strength of this study was the attention it paid to fathers and their roles in the family, and the results indicated that fathers participated more in caring for infants and meeting their needs in the intervention group (12); a fact which would indirectly increase maternal mental health. 
Table 2. Risk of Bias in Included Studies

\begin{tabular}{|c|c|c|}
\hline Bias & Authors' Judgment & Support for Judgment \\
\hline \multicolumn{3}{|l|}{ Melnyk (2001) } \\
\hline Random sequence generation (selection bias) & low risk & $\begin{array}{l}\text { "Participants were assigned to the COPE group or a comparison group by } \\
\text { randomized blocks of time." }\end{array}$ \\
\hline Allocation concealment (selection bias) & Unclear risk & No specific information regarding allocation concealment was given. \\
\hline Blinding of personnel (performance bias) & High risk & It was not possible to blind the personnel. \\
\hline Blinding of participants (performance bias) & High risk & It was not possible to blind the participants \\
\hline Blinding of outcome assessment (detection bias) & Unclear risk & Blinding of assessors not mentioned \\
\hline Incomplete outcome data (attrition bias) & High risk & $\begin{array}{l}\text { "Of the } 55 \text { enrolled mothers, } 13 \text { were lost from the study because of: unanticipated } \\
\text { rapid transfer from the NICU to an outlying hospital }(n=5) \text {; a personal decision to } \\
\text { withdraw from the hospital phase of the study }(n=1) \text {; a personal decision to } \\
\text { withdraw from the post hospital phase of study }(n=3) \text {; failure to keep appointments } \\
\text { for study contacts }(n=3) \text { and transfer of infant custody from mother to grandmother } \\
(n=1) \text {." Analyzes of data were done with } 42 \text { samples. }\end{array}$ \\
\hline Selective reporting (reporting bias) & Unclear risk & - \\
\hline \multicolumn{3}{|l|}{ Melnyk(2006) } \\
\hline Random sequence generation (selection bias) & Low risk & $\begin{array}{l}\text { "A randomized controlled trial was conducted in which subjects at each of the two } \\
\text { study sites were randomly assigned to be in either the cope program or a } \\
\text { comparison intervention program." There was no specific information about type of } \\
\text { randomization. }\end{array}$ \\
\hline Allocation concealment (selection bias) & Low risk & $\begin{array}{l}\text { "The random assignment was hidden from the enrolling research assistants until } \\
\text { after informed consent was obtained." }\end{array}$ \\
\hline Blinding of personnel (performance bias) & High risk & It was not possible to blind the personnel. \\
\hline Blinding of participants (performance bias) & High risk & It was not possible to blind the participants \\
\hline Blinding of outcome assessment (detection bias) & Low risk & Conservationists were blinded to study groups. \\
\hline Incomplete outcome data (attrition bias) & low risk & $\begin{array}{l}\text { "Subjects were analyzed in the study group to which they were originally assigned } \\
\text { (intention to treat analysis)" }\end{array}$ \\
\hline Selective reporting (reporting bias) & Unclear risk & - \\
\hline \multicolumn{3}{|l|}{ Borimnejad (2013) } \\
\hline Random sequence generation (selection bias) & Low Risk & "Randomization was performed using a computer generated table of numbers" \\
\hline Allocation concealment (selection bias) & Unclear Risk & No specific information regarding allocation concealment was given. \\
\hline Blinding of personnel (performance bias) & High risk & It was not possible to blind the personnel. \\
\hline Blinding of participants (performance bias) & High risk & It was not possible to blind the participants. \\
\hline Blinding of outcome assessment (detection bias) & Unclear Risk & No specific information regarding allocation concealment was given. \\
\hline Incomplete outcome data (attrition bias) & Low risk & All participants completed the study. \\
\hline Selective reporting (reporting bias) & Unclear Risk & \\
\hline \multicolumn{3}{|l|}{ Mianaei (2014) } \\
\hline Random sequence generation (selection bias) & Low Risk & $\begin{array}{l}\text { "Mothers who agreed to participate were randomly assigned to the study conditions } \\
\text { by using the RAND function in Excel 2007." }\end{array}$ \\
\hline Allocation concealment (selection bias) & Unclear Risk & No specific information regarding allocation concealment was given. \\
\hline Blinding of personnel (performance bias) & High risk & It was not possible to blind the personnel. \\
\hline Blinding of participants (performance bias) & High risk & It was not possible to blind the participants \\
\hline Blinding of outcome assessment (detection bias) & Unclear Risk & No specific information regarding blinding of assessors was given. \\
\hline Incomplete outcome data (attrition bias) & Unclear Risk & No specific information regarding intention to treat analyzes was given. \\
\hline Selective reporting (reporting bias) & Unclear Risk & - \\
\hline
\end{tabular}



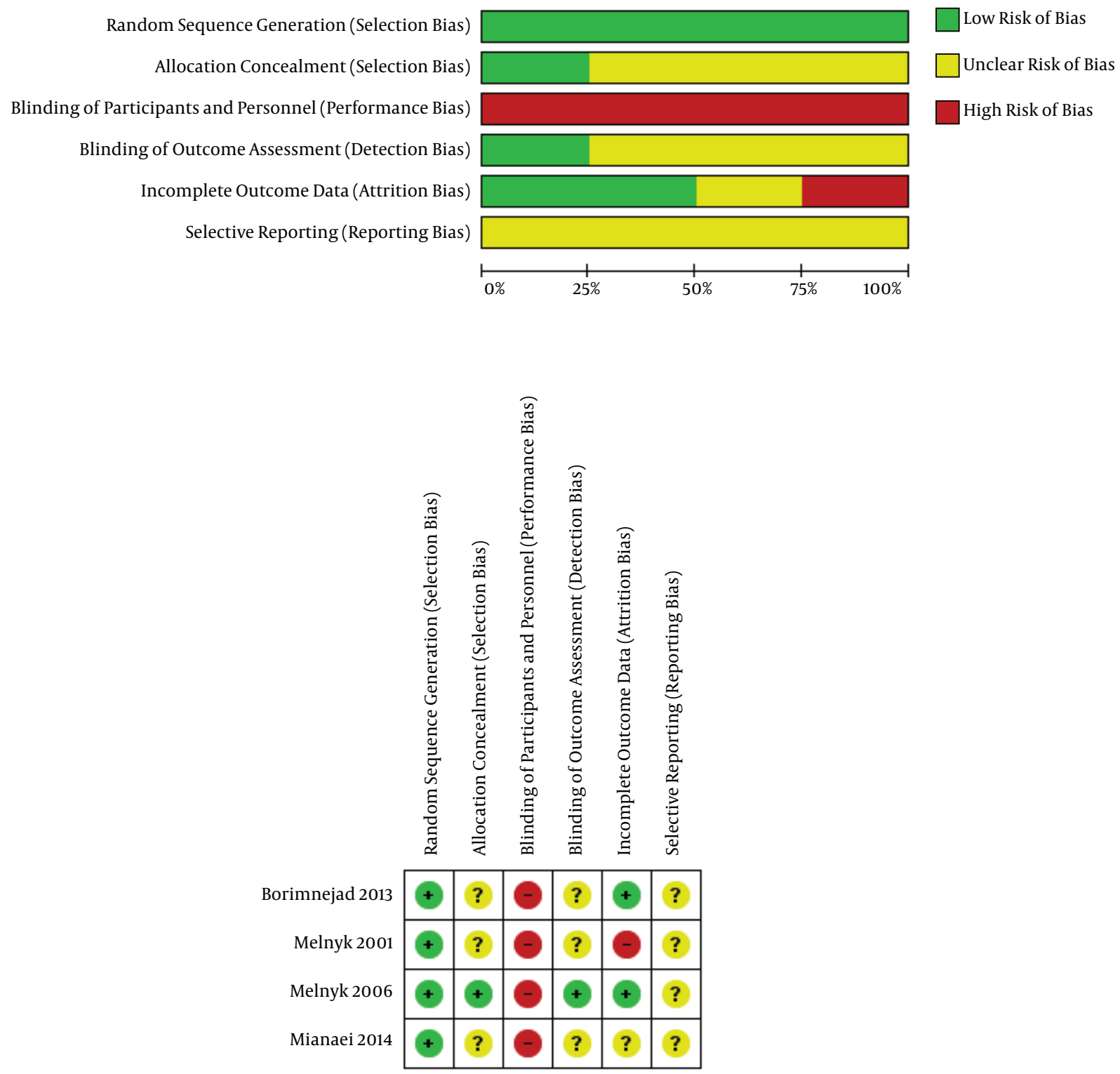

Figure 1. Diagram of Bias in the Included Studies

In 2008, Melnyk conducted another study, which was in fact a secondary analysis of the data obtained from the aforementioned study, and indicated that the COPE program also had a positive impact on the mental health of mothers in the long term (two months after discharging the infant). Moreover, the stress and anxiety levels were lower among the mothers of the control group (19).

In 2014, Oswalt conducted another secondary analysis on the data obtained from the study carried out by Melnyk (2006) and divided the mothers into two age groups.
The first group included those, who were 21 years old and younger, whereas the second one consisted of those older than 21. The results of this analysis indicated that participation in the COPE program reduced the anxiety of younger mothers, two to four days after the intervention (20). This result revealed the importance of implementing empowerment programs at such critical times in young and inexperienced mothers.

In the study conducted by Borimnejad et al. on 140 mothers in Tehran, Iran, in 2013, the intervention group 


\begin{tabular}{|c|c|c|c|c|c|c|c|c|c|}
\hline \multirow{3}{*}{$\frac{\text { Study or Subgroup }}{\text { Melnyk } 2001}$} & \multicolumn{3}{|c|}{ COPE } & \multicolumn{3}{|c|}{ Control } & \multicolumn{2}{|r|}{ std. Mean Difference } & \multirow{2}{*}{$\begin{array}{l}\text { std. Mean Difference } \\
\text { IV, Randome, 95\% CI }\end{array}$} \\
\hline & Mean & SD & Total & Mean & SD & Total & Weight & IV, Randome, $95 \% \mathrm{CI}$ & \\
\hline & 3.1 & 1.3 & 20 & 3.7 & 1.1 & 22 & $0.0 \%$ & $-0.49[-1.11,0.12]$ & \\
\hline Melnyk 2006 & 1.76 & 0.12 & 147 & 1.98 & 0.13 & 113 & $73.2 \%$ & $-1.76[-2.05,-1.47]$ & \\
\hline Mianaei 2014 & 71.2 & 26.91 & 45 & 114.76 & 26.96 & 45 & $26.8 \%$ & $-1.60[-2.08,-1.13]$ & - \\
\hline Total $(95 \% \mathrm{CI})$ & & & 192 & & & 158 & $100.0 \%$ & $-1.72[-1.97,-1.47]$ & $\uparrow$ \\
\hline \multicolumn{6}{|c|}{$\begin{array}{l}\text { Heterogeneity: } \mathrm{Tau}^{2}=0.00 ; \mathrm{Chi}^{2}=0.31, \mathrm{df}=1(\mathrm{P}=0.58) ; \mathrm{I}^{2}=0 \% \\
\text { Test for Overall Effect: } \mathrm{Z}=13.64(\mathrm{P}<0.00001)\end{array}$} & & & & $\begin{array}{ccccc}1 & 1 & 1 & 1 & 1 \\
-4 & -2 & 0 & 2 & 4 \\
& \text { COPE } & \text { Control }\end{array}$ \\
\hline
\end{tabular}

Figure 2. Meta-Analysis of Stress in Phase Two

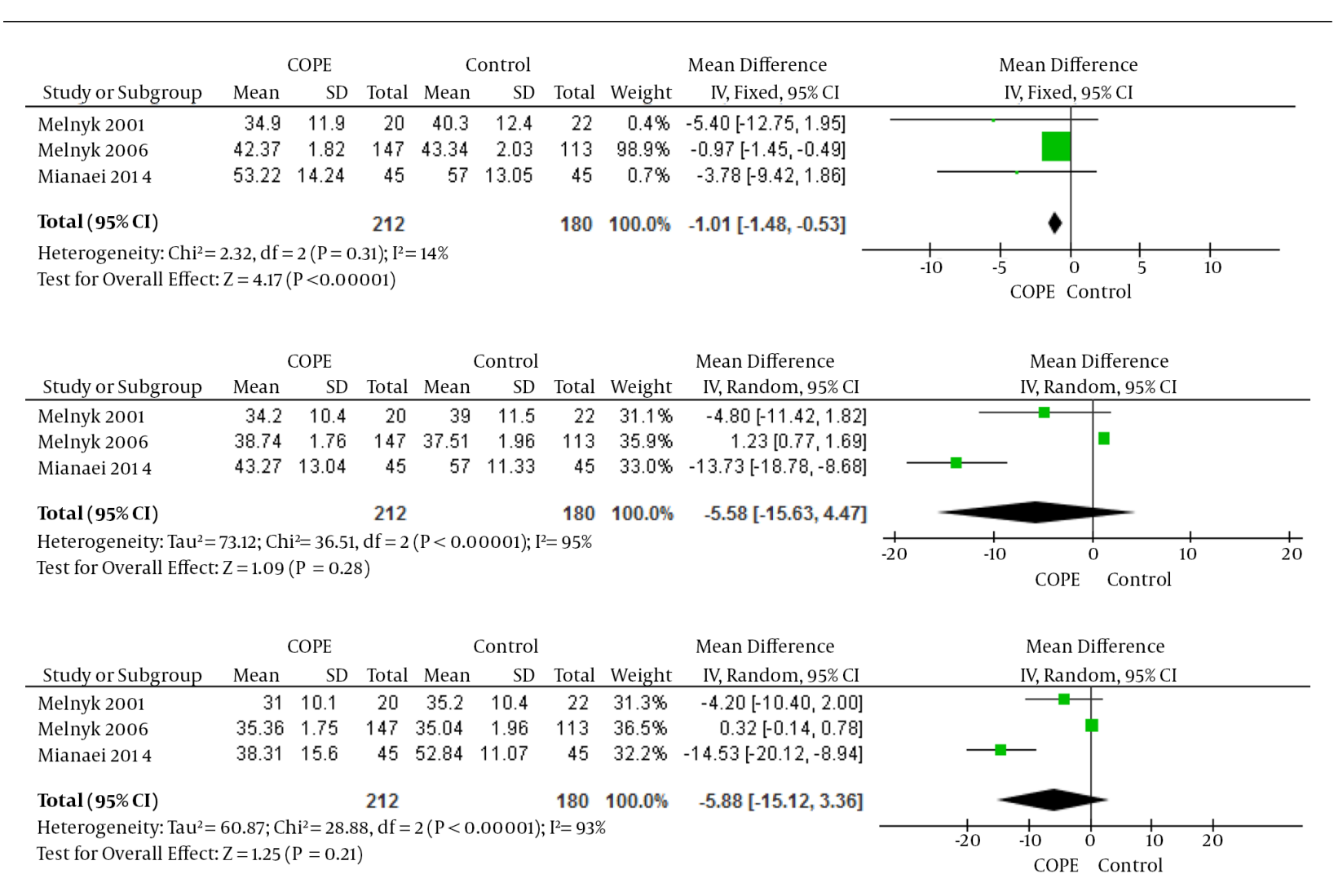

Figure 3. Meta-Analysis of State Anxiety in Phase One, Two and Three

\begin{tabular}{|c|c|c|c|c|c|c|c|c|c|c|c|c|}
\hline \multirow{3}{*}{$\frac{\text { Study or Subgroup }}{\text { Melnyk } 2001}$} & \multicolumn{3}{|c|}{ COPE } & \multicolumn{3}{|c|}{ Control } & \multirow{2}{*}{\multicolumn{3}{|c|}{$\begin{array}{c}\text { Mean Difference } \\
\text { Weight IV, Randome, 95\% CI }\end{array}$}} & \multirow{2}{*}{\multicolumn{2}{|c|}{$\begin{array}{c}\text { Mean Difference } \\
\text { IV, Randome, 95\% CI }\end{array}$}} & \\
\hline & Mean & SD & Total & Mean & SD & Total Weight & & & & & & \\
\hline & 40.6 & 8.5 & 20 & 34.5 & 9.8 & 22 & $18.0 \%$ & $6.10[0.56,11.64]$ & & & $\longrightarrow$ & \\
\hline Melnyk 2006 & 36.56 & 1.62 & 147 & 36.16 & 1.82 & 113 & $56.4 \%$ & $0.40[-0.03,0.83]$ & & & & \\
\hline Mianaei 2014 & 44.44 & 10.06 & 45 & 45.47 & 10.12 & 45 & $25.6 \%$ & $-1.03[-5.20,3.14]$ & & & & \\
\hline Total (95\% CI) & & & 212 & & & 180 & $100.0 \%$ & $1.06[-1.78,3.90]$ & & & & \\
\hline $\begin{array}{l}\text { Heterogeneity: } \mathrm{Tau}^{2} \\
\text { Test for Overall Effec }\end{array}$ & $\begin{array}{l}=3.68 ; \mathrm{C} \\
\mathrm{t}: \mathrm{Z}=0 .\end{array}$ & $\begin{array}{l}h^{2}{ }^{2}=4 \\
73(P=\end{array}$ & $\begin{array}{l}1.52, \mathrm{df} \\
=0.46)\end{array}$ & $=2(P=$ & $=0.10)$; & $I^{2}=56 \%$ & & & -20 & -10 & 10 & 20 \\
\hline
\end{tabular}

Figure 4. Meta-Analysis of Trait Anxiety in Phase 1 
reported less stress than the control group (7). However, the implementation phases of the COPE program were not clearly explained.

Minaei et al. (2014) conducted a study in Isfahan, Iran, and indicated a reduction in maternal stress and anxiety in the intervention group, although all the phases of the COPE program were not implemented (phases three and four). It was also carried out with a small sample size in the state-run hospitals in which the majority of samples had an education less than a high-school diploma and low incomes (4). Therefore, the results could not be generalized.

There was no explanation for the allocation concealment or blindness of assessors in any of the included studies, and no intention to treat evaluation.

The strengths of the papers investigated in this review included the fact that most of them were RCTs; they had strong theoretical frameworks to direct the interventions and select relevant variables; and they used standard tools to measure dependent variables. All studies investigated in this systematic review had control groups, and the conducted intervention was easily implemented.

The weak point of this study was that the studies, which were evaluated in this systematic review, were selected among the Persian and English papers from 2000 until 2015. Perhaps, if all the languages and periods of time had been investigated, more studies would have been found in this regard.

It is recommended to conduct more studies with larger sample sizes on this subject, involving fathers in the intervention, and appraising the long-term outcomes in the mental health of parents and children, the development of children, and the cost-effectiveness of the COPE program.

\subsection{Conclusion}

Evidence from studies indicates that premature birth has adverse impacts on the mental health of parents, especially mothers. The implementation of the COPE program accompanied by training and empowerment of parents can reduce such outcomes to a great extent. Not only the routine use of the COPE program in NICUs improves the mental health of parents, but also it can increase the ability of health care providers to offer a family-based care, which is considered to be a very sensitive and important component in caring for high-risk infants.

\section{References}

1. Melnyk BM, Alpert-Gillis L, Feinstein NF, Fairbanks E, Schultz-Czarniak J, Hust D, et al. Improving cognitive development of low-birth-weight premature infants with the COPE program: a pilot study of the benefit of early NICU intervention with mothers. Res Nurs Health. 2001;24(5):373-89. doi:10.1002/nur.1038. [PubMed: 11746067].
2. Mathews TJ, Minino AM, Osterman MJ, Strobino DM, Guyer B. Annual summary of vital statistics: 2008. Pediatrics. 2011;127(1):146-57. doi: 10.1542/peds.2010-3175. [PubMed: 21173001].

3. Ebrahimi S, Haghbin S, PoorMahmoodi A. Incidence and etiologic fac tors of prematurity [ in Persian ]. Armaghan Danesh. 2001;3(19-20):3941.

4. Mianaei SJ, Karahroudy FA, Rassouli M, Tafreshi MZ. The effect of Creating Opportunities for Parent Empowerment program on maternal stress, anxiety, and participation in NICU wards in Iran. Iran J Nurs Midwifery Res. 2014;19(1):94-100. [PubMed: 24554967].

5. Beheshtipour N, Baharlu SM, Montaseri S, Razavinezhad Ardakani $\mathrm{SM}$. The effect of the educational program on Iranian premature infants' parental stress in a neonatal intensive care unit: a double-blind randomized controlled trial. Int J Community Based Nurs Midwifery. 2014;2(4):240-50. [PubMed: 25349867].

6. Grosik C, Snyder D, Cleary GM, Breckenridge DM, Tidwell B. Identification of internal and external stressors in parents of newborns in intensive care. Perm J. 2013;17(3):36-41. doi: 10.7812/TPP/12-105. [PubMed: 24355889].

7. Borimnejad L, Mehrnoosh N, Fatemi NS, Haghani H. Impacts of creating opportunities for parent empowerment on maternal stress: A quasi-experimental study. Iran J Nurs Midwifery Res. 2013;18(3):218-21. [PubMed: 23983758].

8. Johnson J, Fieler V, Jones L. Self-regulation theory: Applying theory to practice. Pittsburgh, PA: Oncology Nursing Press; 1997.

9. Leventhal $\mathrm{H}$, Johnson JE. Laboratory and field experimentation: Development of a theory of self-regulation. Behav sci nur theory. 1983:189262.

10. Carver CS. A cybernetic model of self-attention processes. Journal of Personality and Social Psychology. 1979;37(8):1251-81. doi: 10.1037/00223514.37.8.1251.

11. Melnyk BM, Alpert-Gillis LJ. The COPE program: a strategy to improve outcomes of critically ill young children and their parents. Pediatr Nurs. 1998;24(6):521-7. [PubMed: 10085993].

12. Melnyk BM, Feinstein NF, Alpert-Gillis L, Fairbanks E, Crean HF, Sinkin RA, et al. Reducing premature infants' length of stay and improving parents' mental health outcomes with the Creating Opportunities for Parent Empowerment (COPE) neonatal intensive care unit program: a randomized, controlled trial. Pediatrics. 2006;118(5):1414-27. doi: 10.1542/peds.2005-2580. [PubMed: 17043133].

13. Melnyk BM, Feinstein NF. Reducing hospital expenditures with the COPE (Creating Opportunities for Parent Empowerment) program for parents and premature infants: an analysis of direct healthcare neonatal intensive care unit costs and savings. Nurs Adm Q. 2009;33(1):32-7. doi: 10.1097/01.NAQ.0000343346.47795.13. [PubMed: 19092521].

14. Melnyk BM, Alpert-Gillis L, Feinstein NF, Crean HF, Johnson J, Fairbanks E, et al. Creating opportunities for parent empowerment: program effects on the mental health/coping outcomes of critically ill young children and their mothers. Pediatrics. 2004;113(6):597-607. [PubMed: 15173543].

15. Melnyk BM, Feinstein NF, Fairbanks E. Effectiveness of informational/behavioral interventions with parents of low birth weight (LBW) premature infants: an evidence base to guide clinical practice. Pediatr Nurs. 2002;28(5):511-6. [PubMed: 12424989].

16. Melnyk BM, Feinstein N, Fairbanks E. Two decades of evidence to support implementation of the COPE program as standard practice with parents of young unexpectedly hospitalized/critically ill children and premature infants. Pediatr Nurs. 2006;32(5):475-81. [PubMed: 17100079].

17. Lopez GL, Anderson KH, Feutchinger J. Transition of premature in fants from hospital to home life. Neonatal Netw. 2012;31(4):207-14. [PubMed: 22763247].

18. Higgins J, Green S. Cochrane Handbook for Systematic Reviews of Interventions. 5 ed. London, UK: The Cochrane Collaboration; 2011 
19. Melnyk BM, Crean HF, Feinstein NF, Fairbanks E. Maternal anxiety and depression after a premature infant's discharge from the neonatal intensive care unit: explanatory effects of the creating opportunities for parent empowerment program. Nurs Res. 2008;57(6):383-94. doi: 10.1097/NNR.ob013e3181906f59. [PubMed: 19018213].
20. Oswalt KL, McClain DB, Melnyk B. Reducing anxiety among children born preterm and their young mothers. MCN Am J Matern Child Nurs. 2013;38(3):144-9. doi:10.1097/NMC.0b013e318286140c. [PubMed: 23625101]. 